\title{
RESPONSIBILITY CENTRES' ROLE IN PRACTICING A PERFORMING MANAGEMENT
}

\author{
Professor PhD Briciu Sorin, University “1 $1^{\text {st }}$ December 1918”, Alba Iulia, sbriciu@yahoo.com
}

Abstract: A responsibility centre corresponds to an inferior level of responsibility for the enterprise and, in the same time, it is the base for calculating the performances of the one responsible with the accomplishment of the undertaken tasks. From the economic viewpoint, the responsibility centres can be classified into profit centres and costs centres. The profit centres can be considered those divisions of an enterprise, which are realizing in fact the outlet, such as the basis wards. The costs centres are those divisions of an enterprise, which are determining only the expenses (costs). From budgeting the profit and cost centres, meaning the responsibility centres, we can forecast the complete posts regarding the determination of the supplying prices. The budget laying down methodology supposes the following steps: A. Elaborating the outlet cost's budget; B. Elaborating the general administrating expenses budget; $C$. Elaborating the marketing expenses budget.

Enterprise's goals achievement is materialized for each structural level, which imposes the forecasts' study on enterprise's divisions, called responsibility centres.

The responsibility centre is regarded as "an interconnected elements ensemble, which is forming an entirety, having a certain autonomy level in using and optimizing the resources available" .

A responsibility centre corresponds to an inferior level of responsibility for the enterprise and, in the same time, it is the base for calculating the performances of the one responsible with the accomplishment of the undertaken tasks ${ }^{2}$.

Usually, a responsibility centre can be assimilated to a managerial entity having precise structural characteristics. It is defined as an ensemble in one physic person's responsibility, as an official service provided with self-means, which are allowing it to accomplish its attributions and goals $^{3}$.

Considering that available grouping of the responsibility centres are not valid if the units specific and their structure relieve a diversity of possibilities.

Some authors delimitate partial and global responsibility centres depending on the main purchases. From the economic viewpoint, the responsibility centres can be classified into:

- Profit centres;

- Costs centres.

The profit centres can be considered those divisions of an enterprise, which are realizing in fact the outlet, such as the basis wards. It is the strategic link where we can calculate the profit as a difference between the revenues and expenses.

The costs centres are those divisions of an enterprise, which are determining only the expenses (costs) - in this case we can control only the costs' level. The responsibility centres structure can be illustrated as it follows in the next diagram:

\footnotetext{
${ }^{1}$ Costache Rusu, Monica Voicu, Management Based on Responsibility Centers, Economic Printing House, Bucharest, 2001, p. 15;

${ }^{2}$ Aslau T., Administrating Control Beyond Appearances, Economic Printing House, Bucharest, 2001, p. 115;

${ }^{3}$ Processing after Ch. Guyon, Coordinating, Controle de gestion, Vol. 2, Masson, Paris, 1989, p. 47;
} 


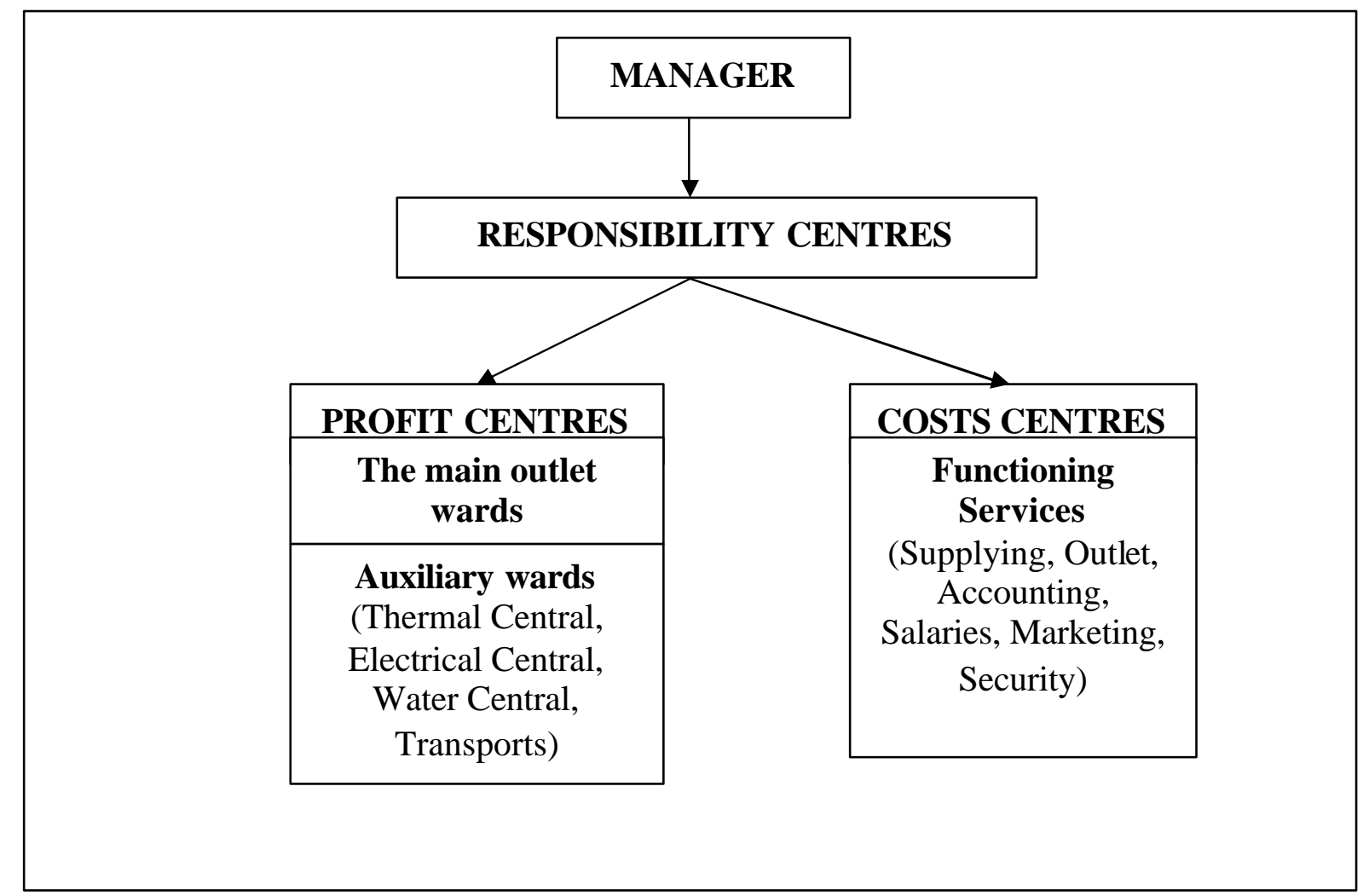

Figure no. 1. Responsibility centres structuring into profit and costs centres.

Regarding the costs calculation depending on costs' centres, we have to specify that, the structure is particular depending on the outlet's specific and enterprise's organizational framework. The costs centres represent "the enterprise's technique, productive, organizational and managing frame's divisions, depending on which is organized the planning and analytic supervising of the outlet expenses"4. The concrete result of the outlet process is individualized in costs' calculation, designated as 'costs' bearers, represented through products, works and services dotained in the outlet process, which have generated the exploitation expenses for which the cost is determined and the activity's supervising is realized also"5. The costs' calculation structure regards the costs' centres (productive wards) in which the costs are allocated on different bearers.

The costs bearer accomplishes the individual costs identifying function, as well as the control function regarding the enterprise's activity volume.

Excepting the costs and profit centres there are revenues centres, as divisions generating revenues (for example, the sells department) or investment centres, which reflects the revenues from the outlet selling, and as well, the investments done for the outlet finality.

The profit centres are the ones that generate revenues able to cover entirely the activity's expenses, and finally obtaining an over income, meaning a profit ${ }^{6}$.

The cost centres have only maximum limits for the expenses that are ensuing from a normal activity.

From budgeting the profit and cost centres, meaning the responsibility centres, we can forecast the complete posts regarding the determination of the supplying prices.

The budget laying down methodology supposes the following steps:

\footnotetext{
${ }^{4}$ Carstea Gheorghe, Oprea Calin, Administrating Accounting and Costs' Calculation, Genicod Printing House, Bucharest, 2002, p. 54;

${ }^{5}$ Victoria Barbacioru, Costs' Calculation, Craiova University's Printing House, 1983, p. 39;

${ }^{6}$ Sorin Briciu, The management accounting. Theoretical and practical aspects, Economic Printing House, Bucharest, 2006, p. 69;
} 
A. Elaborating the outlet cost's budget (ward cost), which includes:

- Raw materials direct expenses' budget;

- Salaries and accessories direct expenses budget;

- Outlet indirect expenses budget (outlet administrating expenses);

B. Elaborating the general administrating expenses budget;

C. Elaborating the marketing expenses budget.

Synthetically the complete commercial cost's budget can be presented as it follows:

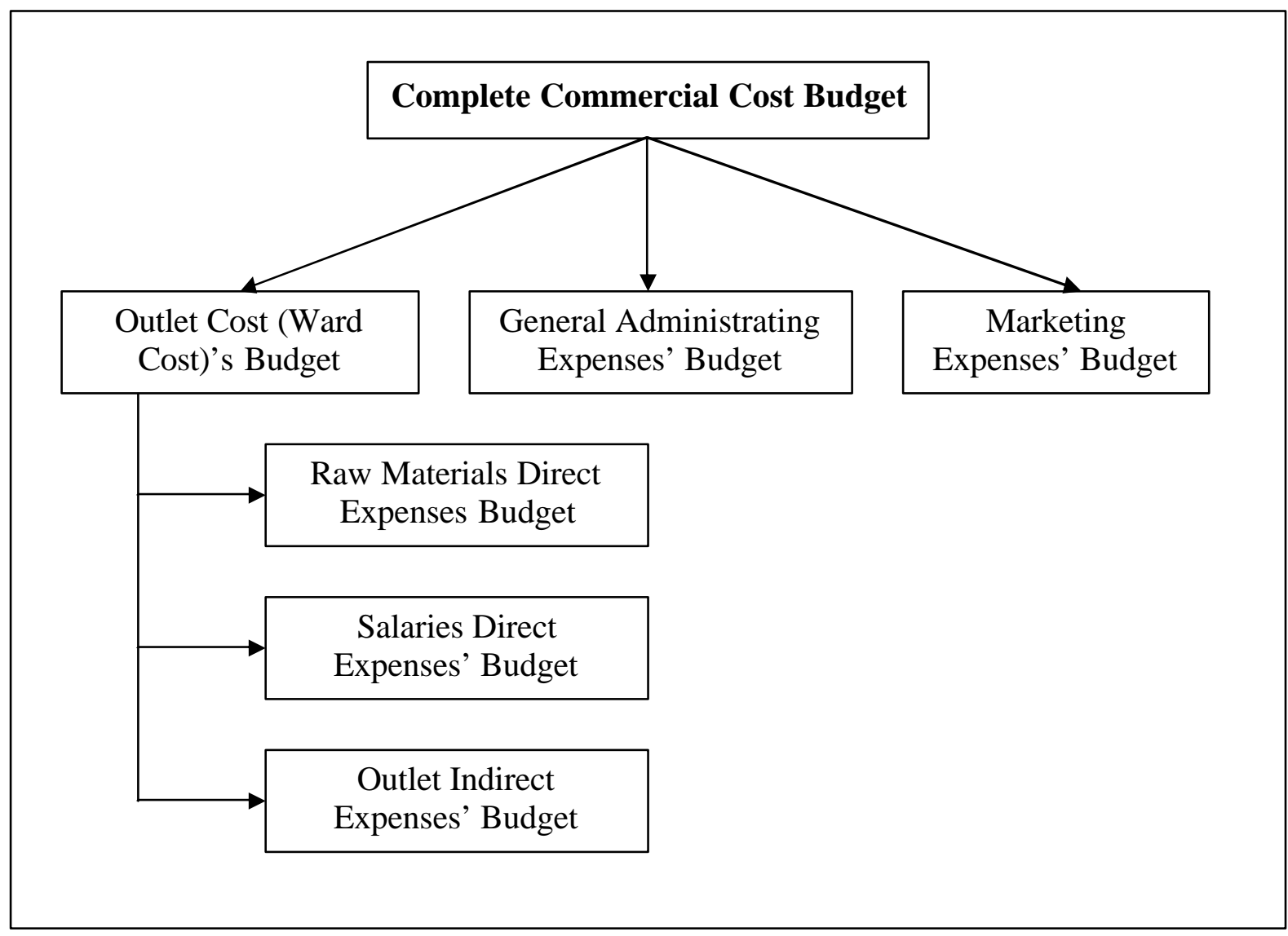

Figure no. 2. Complete Commercial Cost's Budget

The complete commercial cost's budget can be determined by using the following mathematical models:

$$
\mathbf{B}_{\mathrm{CCC}}=\mathbf{B}_{\mathrm{OC}}+\mathbf{B}_{\mathrm{GAE}}+\mathbf{B}_{\mathrm{ME}}
$$

Where:

$\mathrm{B}_{\mathrm{CCC}}$ - Complete Commercial Cost's Budget;

$\mathrm{B}_{\mathrm{OC}}$ - Outlet Cost's Budget;

$\mathrm{B}_{\mathrm{GAE}}-$ General Administrating Expenses' Budget;

$\mathrm{B}_{\mathrm{ME}}$ - Marketing Expenses' Budget.

A. Outlet Cost's Budget $\left(\mathrm{B}_{\mathrm{OC}}\right)$ - it includes the direct outlet expenses' budget and indirect outlet expenses' budget, and is calculated as it follows:

Where:

$$
\mathbf{B}_{\text {OC }}=\mathbf{B}_{\text {DE }}+\mathbf{B}_{\text {OIE }}
$$

$\mathrm{B}_{\mathrm{DE}}$ - Direct Expenses' Budget;

B OIE -Outlet Indirect Expenses' Budget.

Direct Expenses' Budget $\left(\mathrm{B}_{\mathrm{DE}}\right)$ includes the raw materials direct expenses' budget and the direct salaries expenses' budget. So:

$$
\mathbf{B}_{\mathrm{DE}}=\mathbf{B}_{\mathrm{RMDE}}+\mathbf{B}_{\mathrm{SDE}}
$$


Where:

$\mathrm{B}_{\mathrm{RMDE}}$ - Raw Material Direct Expenses’ Budget;

$\mathrm{B}_{\mathrm{SDE}}$ - Salaries Direct Expenses' Budget.

Raw Material Direct Expenses' Budget $\left(\mathrm{B}_{\mathrm{RMDE}}\right)$ - is determined based upon the technological consumption's norms and the acquisition/outlet's costs of the raw materials and direct materials.

Where:

$$
\mathbf{B}_{\mathrm{RMDE}}=\mathbf{Q} * \mathbf{?} \mathbf{n c}_{\mathbf{i}} * \mathbf{c}_{\mathbf{i}}
$$

Q - Fabricated product quantity;

$\mathrm{nc}_{\mathrm{i}}$ - Technological consumption norm for i material;

$\mathrm{c}_{\mathrm{i}}$ - Acquisition/outlet cost for the i material;

$\mathrm{n}$ - Used materials' number.

The budget's measure determined before considers the finished good obtained quantity. For the average (per unit) determination of the budget we report the obtained amount at the outlet's volume.

Salaries Direct Expenses' Budget $\left(\mathrm{B}_{\mathrm{SDE}}\right)$ - it is established considering the time norms for realizing the operations necessary for costs' bearers outlet and the hourly tariffs corresponding to each operation.

Where:

$$
\mathbf{B}_{\mathrm{SDE}}=\mathbf{Q} * \mathbf{n n t}_{\mathbf{i}} * \mathbf{t}_{\mathbf{i}}
$$

$\mathrm{nt}_{\mathrm{i}}$ - time norm corresponding for the i operation;

$t_{i}$ - hourly tariff for the i operation;

$\mathrm{n}$ - The necessary number of operations for the product's fabrication

Outlet Indirect Expenses' Budget $\left(\mathrm{B}_{\mathrm{OIE}}\right)$ - is determined for each ward separately. It supposes the added of the installations maintenance and functioning expenses with the general expenses of the ward, as it follows:

Where:

$$
\mathbf{B}_{\text {OIE }}=\mathbf{B}_{\text {MFE }}+\mathbf{B}_{\text {WGE }}
$$

$\mathrm{B}_{\mathrm{MFE}}$ - Installations Maintenance and Functioning Expenses' Budget;

B ${ }_{\mathrm{WGE}}$ - Ward's General Expenses' Budget.

At the enterprise's level the total outlet indirect expenses' budget is obtaining through the addition of the outlet indirect budget with the outlet wards budgets. Mathematically:

Where:

$$
\mathbf{B}_{\text {TOIE }}=\mathbf{B}_{\text {OIE1 }}+\mathbf{B}_{\text {OIE2 }}+\ldots+\mathbf{B}_{\text {OIEn }}=\text { ? } \mathbf{B}_{\text {OIEi }}
$$

$\mathrm{B}_{\mathrm{TOIE}}$ - Total Outlet Indirect Expenses' Budget;

B ${ }_{\text {OIEi }}$ - Outlet Indirect Expenses' Budget for the i ward;

$\mathrm{n}$ - The enterprise's wards number.

If we consider the two elements of the outlet indirect expenses' budget, then the formula above is becoming:

Where:

$$
\mathbf{B}_{\mathrm{TOIE}}=? \mathrm{~B}_{\mathrm{OIEi}}=?\left(\mathrm{~B}_{\mathrm{MFEi}}+\mathbf{B}_{\mathrm{WGEi}}\right)
$$

$\mathrm{B}_{\mathrm{TOIE}} \mathrm{i}$ - Installations Maintenance and Functioning Expenses' Budget for the $\mathrm{i}$ ward;

$\mathrm{B}_{\text {WGE }} \mathrm{i}$ - Ward's General Expenses Budget for the i ward.

Installations Maintenance and Functioning Expenses' Budget $\left(\mathrm{B}_{\mathrm{MFEi}}\right)$ - includes:

- Technological installations and transportation means' maintenance and functioning, technique reviews and current reparations expenses for the ward;

- Expenses regarding the depreciation of the technologic installations and transportation means of the ward;

- Expenses regarding the depreciation of the special destination installations and the inventory objects of the ward; 
- Expenses regarding the energy, fuel and other expenses with the materials used for technological goals of the ward;

- Other expenses regarding the installations' maintenance and functioning and the transportation means of the ward.

Ward's General Expenses Budget (B $\mathrm{B}_{\mathrm{WGE}}$ ) - includes two budgets: the general interest expenses' budget of the ward and husbandry expenses' budget.

The first one includes:

- Expenses regarding the salaries and the salaries' accessories of the managing, technique, economic and other specialty personnel;

- Expenses regarding the current reparations of the buildings and other means of general interest of the ward, as well as the capital reparations of the buildings and ward's fixed means;

- Expenses regarding the buildings and other ward's fixed means' depreciation;

- Expenses regarding labor protection inside the ward;

- Other general interest expenses of the ward.

The second budget includes:

- Expenses regarding maintenance and cleaning of the husbandry buildings of the ward;

- Expenses regarding the energy for husbandry use;

- Expenses regarding water, sanitation and for the husbandry needs of the ward;

- Expenses regarding the office materials for the ward's needs;

- Expenses regarding the magazines, books, publications and subscriptions for the ward's needs and the Post's expenses;

- Other husbandry expenses of the ward.

B. General Administrating Expenses' Budget $\left(\mathrm{B}_{\mathrm{GAE}}\right)$ includes the entirety of the general interest expenses and the enterprise's husbandry expenses.

Mathematic it is calculated as it follows:

Where:

$$
\mathbf{B}_{\mathrm{GAE}}=\mathbf{B}_{\mathrm{EGIE}}+\mathbf{B}_{\mathrm{EHE}}
$$

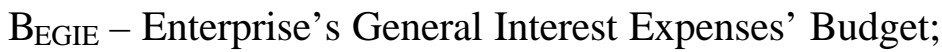

$\mathrm{B}_{\mathrm{EHE}}-$ Enterprise's Husbandry Expenses Bud get.

In the Enterprise's General Interest Expenses' Budget (B $\left.\mathrm{B}_{\mathrm{EGIE}}\right)$ - are included:

- Expenses regarding the salaries and salaries accessories of the managing, technique, economic, other specialty, administrative, service and security personnel of the enterprise;

- Expenses regarding the buildings current reparations;

- Expenses regarding the depreciation of the enterprise's fixed means;

- Expenses regarding the researches, experiences, studies, investments and general interest innovations;

- Expenses regarding the ge neral labor protection;

- Expenses regarding enterprise's interest rates;

- Other enterprise's expenses (personnel transportation's cost, buildings' taxes, insurance policies).

The Enterprise's Husbandry Expenses' Budget (B $\left.\mathrm{B}_{\mathrm{EHE}}\right)$ includes:

- Expenses regarding the office's materials;

- Expenses regarding the acquisition of books, magazines and subscriptions;

- Expenses regarding the business travels, detaches or transfers in the country with or without trips abroad for the company's interest;

- Expenses regarding the energy consumption for husbandry goals;

- Post's expenses of the enterprise;

- Expenses regarding the water, sanitation for management and husbandry purposes;

- Others expenses for enterprise's husbandry. 
Depending on the services number and complexity (finances, marketing, personnel) offered by the management can be laid down two or more budgets. Regarding the small companies it can be only one budget.

C. Marketing Expenses' Budget ( $\mathrm{B}_{\mathrm{ME}}$ ) includes the entirety of expenses generated by the outlet selling process, such as:

- Expenses regarding the products' transportation and manipulation, products that are delivered to the internal customers;

- Internal transportation, manipulation, storage, reconditioning and clearance expenses of the products delivered for export;

- Wrapper expenses for the delivered products;

- Advertising expenses.

\section{References:}

1. Allaire Y., Firsirotu M., Strategic Management, Economic Printing House, Bucharest, 1998.

2. Aslau Titus, Administrating Control Beyond Appearances, Economic Printing House, Bucharest, 2001.

3. Barbacioru Victoria, Costs' Calculation, Craiova University's Printing House, 1983.

4. Bistriceanu Gheorghe D., Financing, Banking and Assurance Lexicon, Vol. I-III, Economic Printing House, Bucharest, 2001.

5. Briciu Sorin, Informational System regarding Administrating Accounting and Costs' Calculation in Industry, Argus Printing House, Bucharest, 2000.

6. Briciu Sorin, The management accounting. Theoretical and practical aspects, Economic Printing House, Bucharest, 2006.

7. Calin Oprea, Carstea Gheorghe, Administrating Accounting and Costs' Calculation, Genicod Printing House, Bucharest, 2002.

8. Cristea Horia, Accounting and Calculations in Enterprise's Management, Mirton Printing House, Timisoara, 1997.

9. Ebbeken Klaus, Possler Ladislau, Ristea Mihai, Costs' Management and Calculation, Teora Printing House, Bucharest, 2000.

10. Guyon Ch., Coordinating, Controle de gestion, Vol. 2, Masson, Paris, 1989.

11. Rusu Costache, Voicu Monica, Management Based on Responsibility Centers, Economic Printing House, Bucharest, 2001. 